\title{
TANITMA: Marina MacKay, Roman Nedir? İstanbul: Boğaziçi Üniversitesi Yayınları, 2018, 333 s.
}

\section{Gülizar Sinem ÖN KAHVECÍ1}

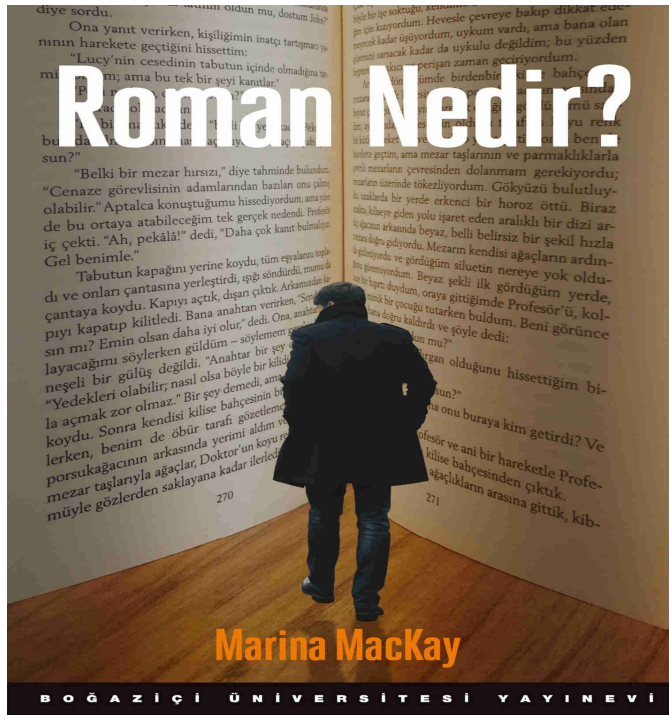

Oxford Üniversitesi'ne bağll St Peter Kolej'de 2014'ten beri İngiliz Edebiyatı üzerine çeşitli dersler veren Marina MacKay, araştırma alanları olarak İngiliz edebiyatı roman tarihi ve politik krizlerin temsili konularına ağırlık verir. MacKay, roman tarihi üzerine çalışmalarını 2011 yılında The Cambridge Introduction to the Novel adiyla Cambridge Üniversitesi Yayınevi aracıllğıyla kitaplaştırır. Orijinal adiyla The Cambridge Introduction to the Novel olan kitap, 2018 yllında Fazilet Akdoğan Özdemir tarafından Türkçeye çevrilir ve Boğaziçi Üniversitesi Yayınevi tarafindan Roman Nedir? adıyla yayımlanır.

Roman Nedir’in kapak tasarımı reklamcı Kerem Yeğin tarafindan yapılır. Yeğin, kitabın kapağında Bram Stoker'ın Dracula eserinin 270. ve 271. sayfalarını kullanır. Bu sayfalarda Van Helsing ve John adlı doktorların mezarlıktaki cesetlerin gizemli kayboluşlarını aydınlatmaya yönelik araştırmalarına yer verilir. Dracula'dan alınan bu sayfaların önünde de yüzü görünmeyen baştan aşağıya siyah giyinmiş bir erkek vardır. Kitabın kapağındaki bu erkeğin arkadan görüntüsü gizli gizli bir şeyler okuyan ya da arayan bir detektif izlenimi vermektedir. Dracula'daki iki araştırmacı doktor, sayfaların önündeki siyah kıyafetli detektif benzeri erkek ve okuyucular; hepsinin de ortak yönleri meraklı olmaları ve sorulara cevap aramalarıdır. Yeğin, Roman Nedir?'in kapağını gizem dolu hikâye ve yüzü görünmeyen bir erkeğin görüntüsüyle tasarlayarak romanın tarihsel serüvenine dair okuyucuda merak uyandırmaya çalışmıştır. Bunlara ek olarak kitabın ilk ve son sayfalarının turuncu renkte basılması kuram kitaplarının ağır havasını hafifletmeye yönelik bir adım olarak algılanabilir.

Eser,'Roman Neden Önemlidir?', 'Romanın Kökenleri', 'Romanın Öykülenişi', 'Karakter ve Roman', 'Romanda Olay Örgüsünün Kuruluşu', 'Romanda Ortam', 'Zaman ve Tarih', 'Tür ve Alttür', 'Roman ve Anti-Roman', 'Roman, Ulus, Cemaat' ve 'Sonuç' başlıklarılla on bir bölümden oluşmaktadır. MacKay, her bölümün sonunda işlediği konuyu seçtiği bir roman üzerinden örneklemeye çalışır ve böylece konunun anlaşılmasına ve de akılda kalmasına yardımcı olur. Seçilen örnek romanlar kronolojik bir düzen içinde verilir. Yazar, Miguel de Cervantes'in Don Quijote'si ve Salman Rushdie'nin Geceyarısı Çocukları adlı eserleri dışında örnek romanlarını İngiliz Edebiyatından seçer. Kitabın sekizinci bölümüne kadar romana ait biçimsel özelliklerden ve romanın öğelerinden bahsedilirken dokuzuncu bölümden on birinci bölüme kadar roman türleri üzerinde durulur. Ana bölümler ve roman örnekleri çoğunlukla bir epigrafla başlar. Ayrıca her bölümde 'aşina olunmayan' bir terim ilk defa kullanılıyorsa bu terim koyu bir şekilde yazılır. Koyu renkte yazılı terimlerin tanımları kitabın sonundaki sözlükçede verilir.

1 Dr. Öğrencisi, İstanbul Medeniyet Üniversitesi, Sosyal Bilimler Enstitüsü, Türk Dili ve Edebiyatı ABD (İstanbul, Türkiye), kahvecigso@gmail.com, ORCID ID: 0000-0001-5973-0532 [Makale kaylt tarihi: 22.11.2019-kabul tarihi: 20.12.2019; DOI: $10.29000 /$ rumelide.657968] 
'Roman Neden Önemlidir?' adlı ilk bölümde kurmaca-olmayan roman, anlatı, karakter, olay örgüsü, ortam, romans, gerçekçi/lik, duygusallık romanı, mektuplu roman, gotik roman, anlatıcı, kanon, alegorik, temsil, modernist, epik, diyalojik, çokdillilik/dışdilsellik, diyalog, alim-i mutlak anlatıcı, parodi, roman kahramanı ve üst kurmaca kelimeleri koyu renkte yazılır. Yazar bu bölümde romanı tarif etmenin zor ve bir o kadar da tehlikeli olduğundan bahseder; çünkü roman için yapılan her genel geçer tarif yeni yazılan bir roman tarafından çürütülebilir. Romanın çeşitli yönlerden zamanla değişkenlik göstermesinin yanında toplumun romana bakış açısı da değişkenlik gösterir. MacKay, 18. yüzyılda romanın yaygınlaşmaya başladığı ilk yıllarda romanın gençlere özelliklere de genç kızlara zararlı olduğunu "kalbe ahlaksızlık ve ahmaklık tohumları ektiğini, tutkuları uyandırdığını, sahte beklentiler yarattığını” (s.13) söyleyen Clara Reeve'in The Progress of Romance (1785) adlı çalışmasındaki ithamlara yer verir. Diğer taraftan MacKay, romanın günümüzde akademik çalışmalara en çok konu olan ve değer verilen türlerden biri olduğunu söyleyerek romanın tarihsel gelişimi ve değişimi hakkında bilgi verir. Bu bölümde ele alınan ana konulardan bir diğeri de romanın gerçeklikle ilişkisidir. Gerçeklik konusunu Cervantes'in Don Quijote'si üzerinden açıklamaya çalışan MacKay, gerçekliğin toplumsal tutuculuk tarafindan belirlendiğinin altını çizer.

'Romanın Kökenleri’nin ele alındığı ikinci bölümde gerçeğe yakınlık, ideoloji, tarihsel roman, epizodik, anekdot, izlek ve anti-roman kelimeleri koyu renkte yazllır. MacKay, Margaret Anne Doody'nin The True Story of The Novel eserinde romanın kökeninin iki bin yllık kümülatif bir geçmişe sahip olduğu düşüncesiyle, Ian Watt'n The Rise of The Novel eserinde romanın kökenini 18. yüzylla dayandırıp kapitalizmle ilişkilendirmesi düşüncesi üzerine yoğunlaşır. MacKay'e göre romanın kökenine dair başlangıç hikâyesi aramak doğallıktan uzaktır: "Edebiyat tarihinde, edebiyatın kendisinde olduğu gibi, açıklayıcı başlangıçlar ve bir şeyleri ortaya çıkaran sonlar albenili olduğu kadar yapaydır da.” (s.62). Yazarın bölümün sonunda örnek olarak, kendi başlangıcını anlatmaya çalışan ama ayrıntılarda boğulduğu için ciltlerce yazmasına rağmen doğumunu bile anlatmaya başlayamayan Tristram'ın (Laurence Sterne'in Tristram Shandy Beyefendi'nin Hayatı ve Görüşleri) hikâyesini seçmesi manidardır.

'Romanın Öykülenişi' konusuna eğinilen üçüncü bölümde kastedilen yazar, kastedilen okur, üçüncü şahıslı anlatı, serbest dolaylı söylem, serbest dolaylı üslup, epigraf, iç monolog, bilinç akışı, roman dizisi, birinci şahıslı anlatı, anlatıbilim, dış anlatıcı, güvenilmez anlatıcı, ideoloji, çerçeveli anlatı, iç içe geçmiş anlatı, duygusal gerilim/sansasyon romanı, kısa roman ve yan metin kelimeleri koyu renkte yazılır. MacKay, bu bölümde Percy Lubbock'un The Craft of Fiction adlı eserinden bir epigraf kullanır. Bu alıntıda, sadece romanın öyküsüne odaklanmaktansa romanın diğer bileşenlerini de bilmenin gerekliliğinden bahsedilir. $\mathrm{Bu}$ bileşenlere ya da Lubbock'un deyişiyle malzemelere; anlatıcı, karakter ve olay örgüsünün kurgulanışı örnek olarak verilir. Bölüm sonunda James Hogg'un Bağışlanmış Bir Günahkârın Özel Anıları ve İtirafları adlı eserin malzemelerine ve nasıl öykülendiğine dair derin bir inceleme yapılır.

'Karakter ve Roman' adlı dördüncü bölümde modernizm, gerçekçi, düz karakter, dairesel karakter, hiciv ve mimetik kelimeleri koyu renkte yazılır. MacKay, David Lodge'un İyi İş adlı eserinden aldığı epigrafla konusuna başlar. Epigrafta Robyn adlı kişi "karakter'in bir burjuva miti, kapitalizm ideolojisini desteklemek için yaratılan bir yanılsama olduğuna inanır.” (s.109). Diğer taraftan Lodge, romanın bir bileşeni olarak karakteri romanın en önemli öğesi olarak görür (s.110). Lodge, eserindeki Robyn vasıtasıyla karakterin önemli olmadığını söylerken kendi görüşüyle karakteri üst bir pozisyona koyarak aslında ortaya iki farklı görüş çıkarmaktadır. MacKay için de karakter önemlidir ve karakter olmadan roman yazmak mümkün değildir. Romanda karakterlerin nasıl yaratılıp 
yorumlandığına dair çeşitli romanlar üzerinden örnekler veren MacKay, E. M. Forster'ın Roman Sanatı eserindeki 'düz ve dairesel karakter' adlı açıklamaları üzerinde durur. Bunlara ek olarak yazar, karakterin metin, işlev ve kişi olarak görülmesiyle ilgili çeşitli örnekler vererek karakterin tanımındaki çok yönlülüğün penceresini aralamaya çalışır. Bölümün sonunda karakter konusu Nathaniel Hawthorne'un Kızıl Harf adlı romanı ele alınarak derin bir incelemeye tabii tutulur.

'Romanda Olay Örgüsünün Kuruluşu' başlı̆̆ını taşıyan beşinci bölümde post-modern, gerilim romanı, askıya alma, Victorya dönemi romanı ve büyülü gerçekçilik kelimeleri koyu renkte yazılır. Bu bölümde romanı okurken oyucunun keyif almasını sağlayan teknik ve taktikler (askıya alma, kesilme ve erteleme) anlatılır. MacKay olay örgüsünü merakımızı uyandıran ayakta tutan ve doyuma ulaştıran bir mekanizma olarak görür (s.138) ve postmodern döneme kadar romanın ayrılmaz bir parçası olduğunu dile getirir (s.155). Olay örgüsü konusu Gustave Flaubert’in Madame Bovary romanıyla ayrıntılı şekilde örneklendirilir.

Pikaresk, sömürgecilik-sonrası, doğalcı, distopya ve alışkanlığın kırılması gibi konuların ele alındığı ‘Romanda Ortam' adlı altıncı bölümde MacKay, ortamın romanın önemli bir öğesi olduğunu ve Bahtin’in düşüncesine (Ortamın, romanı romans ve diğer türlerden ayıran en önemli özelliklerden biri olması) katıldığını dile getirir: "Halbuki benim bu bölümde anlatmak istediğim, romanda ortamın daima gerçekçi olan ile romantik olan arasındaki sınırları kaldırdığıdır: bir yeri yazmak bir yeri hayal etmek, hatta eski bir işaret direğinin etrafında yeni bir yer yaratmaktır.” (s.164). Bölüm, Charles Dickens'ın Kasvetli Ev'i ortam konusu merkezinde detaylı incelenerek sonlandırılır.

'Zaman ve Tarih' adını taşıyan yedinci bölümde anakronizm, kronotop, ileri sıçrama ve geri sıçrama kelimeleri koyu renkte yazılır. MacKay bu bölümde romanın zaman ve tarih içinde insan hayatıyla olan ilgisine ve geniş zamana yayılan tarihsel romanlardan yirminci yüzyl romanlarına (modern roman) kadar anlatı zamanında yaşanılan değişim ve dönüşümlere yer verir. MacKay, romanda zaman ve tarih algısının dönüşümünü daha çok modernist ve postmodernist edebiyata ağırlık vererek anlatır. Bölümün sonunda da İngiliz postmodernist yazarlardan Virginia Woolf un Deniz Feneri romanı üzerinden anlatı zamanının esnekliğine dikkat çekilir.

‘Tür ve Alttür' adlı sekizinci bölümde tür kurmacası, casusluk romanı, dedektif romanı, bilimkurgu romanı ve metinlerarasılık kelimeleri koyu renkte yazılır. MacKay, tür kurmacası ve edebi kurmaca arasında kesin çizgilerin olmadığından aksine birbirleri arasında geçişlerin olduğundan bahseder. Bununla birlikte romana atfedilen "klasik" sıfatının nasıl elde edildiğini ve hangi edebi değer ve belirleyiciler tarafından oluşturulduğunu tartışır. Bölümün sonunda Grahan Greene'nin Korku Bakanlığ eseri incelenir. MacKay'in bu kitabı seçmesinin amacı edebi kurmaca ve tür romanı arasındaki ayrımına ters düşen bir örnek olmasıdır: "Edebi kurmacayı tür romanından ayıran şeyin, birinin hayata, diğerinse başka romanlara benzemesi olduğunu söylemek çok cazip gelse de, bu tam da Korku Bakanhı̆ı'nın altüst ettiği ayrımdır." (s. 237).

'Roman ve Anti-Roman' adlı dokuzuncu bölümde üstkurmaca, müdahaleci anlatıcı ve tarih yazımsal üstkurmaca kelimeleri koyu renkte yazılır. 'Roman, Ulus, Cemaat' adlı onuncu bölümde koyu renkte yazılı kelime bulunmaz. MacKay, 20. yüzyılda romanın tükendiği, öldüğü ve romana dair her şeyin denendiği düşüncesinin romanın modern anlamda gelişmesinin başlangıcı olarak kabul eder (s.243). Büyülü gerçekçiliğin kurmaca dünyasına girmesi, üstkurmacanın yükselişi, yeniden yazma süreçlerinin artması ve postmodernist anlayışın etkinliği romanın yeniden hayat bulmasına katkı 
sağlamıştır. Bu bölümde romandaki değişim ve yenilikleri göstermek adına Thomas Pynchon’ın postmodernist eseri 49 Numaralı Parçanın Nidası örnek olarak incelenir.

"Roman, Ulus, Cemaat” kavramlarının öne çıkarıldığı onuncu bölümde koyu yazılı bir kelime bulunmamaktadır ama Latince 'e pluribus unum' ifadesi bu bölümü anlamak için gereklidir. 'E pluribus unum’ çokluktan birliğe anlamına gelmektedir. Amerika Birleşik Devletleri’nin ilk resmi sloganı olan bu söylem, ABD’nin çoklu halk sisteminin bir çatı altında toplanmasını ifade etmektedir. MacKay, romanın birey üzerinde etkisi olduğu kadar ulusların inşaası ve devamı için de büyük önem arz ettiğini vurgulamaktadır:

"Yani romanlar toplumsal varoluşla ilgili olarak, hatta aynı zamanda toplumsal varoluşun bireysel deneyimleriyle ilgili olarak hem öznel hem de öznelerarası olduğundan, bütün temel edebi türler içinde cemaatleri tasavvur etme ve ebedileştirmeyle en güçlü biçimde ilişkilendirilen türdür.” (s.267).

Bölümün sonunda Salman Rushdie’nin Geceyarısı Çocukları üzerinden çokkültürlülük, melezlik, ulus ve kimlik konuları tartışılır.

‘Sonuç’ bölümünde kapanış kelimesi koyu renkte yazllır. Bu bölümde hem Roman Nedir?’in hem de roman türünün zamanla değişen sonuç kısmına dikkat çekilir. Romanın değişken yapısı karşısında sonuç bölümleri de nasibini alır ve romanlarda süreğenlik ve ucu açık sonlar yerlerini alır. MacKay de çalışmasını "sonuçsuz sonucuma gelmiş bulunuyorum" (s.300) diyerek modern romanların sonlarına paralel bir bitiş yapar.

Nazım Hikmet "Saman Sarısı" adlı şiirinde ressam Abidin Dino'ya "Sen mutluluğun resmini yapabilir misin Abidin" diye seslenir. Bu soru değiştirilerek Marina MacKay’e "Siz romanın tarifini yapabilir misiniz?” diye sorulsaydı; "Önemli romanlar yazılmaya, önemli romancılar yeniden yazllmaya devam ettiği içindir ki, her "romana giriş" kitabı tamamlanmamış bir eserdir." (s. 301) açıklaması sebebiyle bu sorunun cevabı büyük ihtimalle 'hayır' olurdu. Bununla birlikte, romanın resminin ya da yol haritasının çizilmesi konusunda MacKay'in çalışmasındaki koyu renkte yazılmış kelimeler büyük fayda sağlayacaktır. Kısacası MacKay, romanın dinamik ve kendini yenileyen bir yapıya sahip olması sebebiyle romanın değişmez bir tarifinin yapılamayacağını vurgular; fakat diğer taraftan koyu şekilde yazdığı kelimelerle de romanın ne olduğuna dair okuyuculara bir resim çizmiş olur. 